\title{
Modern Investigation toward Shari'ah Compliance: Squatting Uroflowmetry
}

\author{
Muhd Zaki Azre Redzuan ${ }^{1}$, Mohd Nazli Kamarulzaman ${ }^{2}$, Hamid Ghazali ${ }^{1}$ \\ ${ }^{1}$ Department of Urology, Hospital Tengku Ampuan Afzan, Jabatan Urologi, Hospital Tengku Ampuan Afzan, \\ Kuantan, Pahang. \\ ${ }^{2}$ Department of Surgery, Kulliyyah of Medicine, International Islamic University Malaysia Kuantan.
}

\section{ABSTRACT}

INTRODUCTION: Standard uroflowmetry is performed in a standing position and it is an important investigation for those who are suspected of having lower urinary tract symptoms such as benign prostatic hyperplasia (BPH). Effects of changing positions during uroflowmetry have also been investigated previously but mixed conclusions were made. For Muslims, voiding in squatting position is encouraged as part as daily practice. This is mainly due to cleanliness reason and many Hadiths have emphasised about it. Objective: The aim of this study is to compare uroflowmetry findings between squatting and standing positions amongst BPH patients attending urology clinic Hospital Tengku Ampuan Afzan (HTAA). Methods: This is a cross section observational study carried out from March 2015 to December 2015. The maximum flow rate, average flow rate, voiding volume, total voiding time and post-voiding residual volume were measured and recorded. Results: The results were then compared and analysed. $64.2 \%$ of patients were non-Muslims. $78.0 \%$ of the patients voiding habit were standing and $12.2 \%$ squatting position at home. The average International Prostate Symptom Score (IPSS) was 12.07 and $63.4 \%$ of them were in moderate group disease. Post void residual (PVR) volume showed a reduction in squatting position $(p<0.05)$. Otherwise there was no significant difference seen in other parameters. Conclusion: This study showed that voiding in squatting position, which is shari'ah compliant is not inferior compare to standard uroflowmetry. Therefore Muslim patients should be given the option to perform uroflowmetry in a squatting position if available. This may yield better results.

KEYWORDS: Uroflowmetry, Benign Prostatic Hyperplasia, Lower urinary tract symptoms, Voiding Sitting, Voiding Standing.

\section{INTRODUCTION}

The lower urinary tract system is one of the few body systems controlled by both voluntary and autonomic nervous systems involving synchronised interaction between the bladder and the urethra. This results in a complexity of function. ${ }^{1}$ Many factors are involved and affect micturition which are; pressure of abdominal muscles and viscera and its transmission to the bladder and the urethra, relaxation degree of pelvic floor muscles in different position of micturition, and relaxation degree of adductor and anterior muscles of the thigh which directly affects the relaxation of the pelvic floor muscles. ${ }^{2-4}$

Changes in voiding position may have significant impact on the factors mentioned above and hence the control and flow of micturition. ${ }^{3,4}$ In eastern countries such as Malaysia, males are accustomed to voiding in the sitting or squatting position due to habitual and religious issues, in contrast to western countries where voiding is usually achieved in the standing position. ${ }^{5}$

Corresponding author:

Muhd Zaki Azre Redzuan

Department of Urology,

Hospital Tengku Ampuan Afzan,

Jalan Tanah Putih, 25100 Kuantan,

Pahang

Email: nazlikamarulzaman@gmail.com

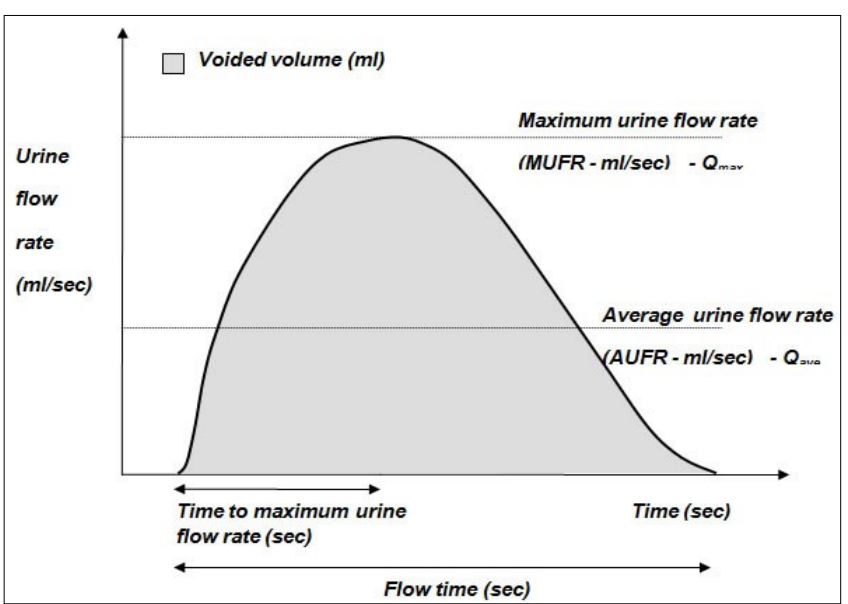

Figure 1: Uroflowmetry Pattern in Normal Subject. ${ }^{2}$

Uroflowmetry is a simple diagnostic screening tool used to calculate the flow rate of urine over time. It is non-invasive, cheap and easy to interpret. The device will calculate the amount of urine, rate of flow and length of time to complete a single micturition. These data will be translated into a graph for interpretation as shows in figure $1 . .^{2,6}$ It is very useful and gives an objective data for detection of any abnormalities in urinary flow either for diagnosis or follow up. There is no known risk for using the device and it can be done in privacy or as 
an outpatient basis. No complicated preparation required such as overnight fasting or sedation. The subjects will only require to have a full bladder by drinking adequate amount of fluids and to hold their urine until the procedures commence. ${ }^{3,4}$

Studies in the literature have addressed the impact of voiding position on uroflowmetry results. ${ }^{2-5}$ These studies have involved both healthy participants and patients with bladder outflow obstruction. Some results favour sitting and squatting positions compared to standing, giving that voiding position is thought to influence urodynamic by affecting angles and cross sectional area of the urethra and meatus. ${ }^{7}$

-10 However there are also studies that showed there were no effects of different voiding positions on uroflowmetry results making the hypothesis inconclusive. ${ }^{11,12}$

\section{METHOD}

The aim of this study is to compare uroflowmetry findings between squatting and standing positions amongst $\mathrm{BPH}$. It is a a prospective cross sectional observational study conducted in BPH patients attending urology clinic Hospital Tengku Ampuan Afzan (HTAA) from March 2015 to December 2015. IPSS of all eligible patients were assessed. Routine physical examinations including digital rectal examination were performed and regular blood testing was all taken. Formal ultrasound of the urinary system were done by radiologists in HTAA and routine bladder scan to measure urine volume before and after uroflowmetry were done by dedicated urology medical assistants who are very familiar with the procedure. Their common habitual positions of voiding were also reviewed.

Eligible subjects were briefed regarding the procedure and written consent obtained. This procedure performed in a specifically designed toilet solely for uroflowmetry recording. Prior to the uroflowmetry, all patients were given a list of standard instruction and checklist on preparation for the test. They were asked to drink at least 200 $\mathrm{mls}$ of water within 1 to 2 hours before procedure or before reaching the clinic on the appointment day and asked to hold their urine until the procedure commenced. This is to ensure patients will have a full bladder and to ensure adequate urine before the procedure and hence more accurate uroflowmetry reading will be obtained. During the procedure they were asked to urinate without increasing abdominal pressure in different positions; standing and squatting using the designated toilet at different times. In each position, urodynamic findings including voided urine volume, voiding time, Qmax and Qave were measured. After uroflowmetry was completed, all patients immediately had an ultrasound for estimation of the PVR volume. Each test was done during a single clinic visit at time interval of one to two hours in between different positions or at different clinic visits however all tests were completed within four weeks.

This study has been approved by the Medical Research and Ethics Committee, Ministry of Health Malaysia with project code of NMMR-14-1604-21988 (IIR). Confidential protections of all the information obtained were protected as per Good Clinical Practice Guidelines Third Edition 2011. ${ }^{13}$

Only BPH patients attending our clinic with age ranges from 50 to 90 years old were included in this study. They must be fit to perform voiding in standing and squatting positions to be eligible. If they are not fit for any reason such as musculoskeletal disability, they are not eligible to participate. Exclusion criteria include prostate cancer, stricture of the urethra/meatus, and history of prostatic surgery, bladder stones, neurogenic bladder dysfunction and active urinary tract infection proven by urinalysis. A minimum of $150 \mathrm{ml}$ of urine in the bladder measured by bladder scan is necessary before the patient can proceed for uroflowmetry study. If the volume is less, the patients were asked to drink more fluids and reassessed.

Statistical analysis was conducted using IBM SPSS Statistics version 23. Descriptive statistics are presented as frequency; and categorical data as percentage, mean and standard deviation. Analysis and comparison of mean uroflowmetry parameters were analysed using paired T-test with 95\% confidence interval. Statistical significance was set at $p<0.05$. No conflict of interest during the period of this study.

\section{RESULTS}

A total of 123 male patients were included in this study. The mean age was 69 years old and $87 \%$ more than 60 years old. Majority were Chinese followed by Malays and Indians with $58.5 \%, 35.0 \%$ and $5.7 \%$ respectively. Normal voiding habit patterns were

Table 1: Uroflowmetry parameters result during standing and squatting positions.

\begin{tabular}{llllll}
\hline Uroflowmetry parameters & Standing & SD & Squatting & SD & $p$-value \\
\hline Qmax & 12.44 & 5.59 & 11.69 & 7.30 & $>0.05$ \\
Qave & 5.42 & 2.55 & 4.67 & 2.48 & $>0.05$ \\
Voiding volume & 236.59 & 135.03 & 199.29 & 104.49 & $>0.05$ \\
Voiding time & 51.34 & 30.45 & 50.46 & 49.18 & $>0.05$ \\
PVR volume & 41.97 & 33.72 & 38.28 & 29.04 & $<0.05$ \\
\hline
\end{tabular}


mostly standing, followed by sitting then squatting; $78 \%, 12.2 \%$ and $9.8 \%$ respectively. Mean duration of diagnosis of BPH in this study group was 5.6 years and about two third of the patients were diagnosed for less than 5 years. $70.7 \%$ of them were on single medical therapy. Average IPSS was 12.07 and $63.4 \%$ of them were in moderate group. The mean size of prostate in this study was $42.95 \mathrm{~g}$ and $70.7 \%$ of patients had estimated prostate size of less than 50 g. $27.27 \%$ of patients had IPP.

Table 1 shows five components of uroflowmetry that are usually reviewed for assessment in bladder outlet obstruction such as BPH. All parameters favour common standing position however they were all not significant. With the exception of PVR volume which showed some significant improvement in squatting position. Further analysis comparing races, common voiding habit, IPSS score, estimated size of prostate and IPP, the results were all similar to overall group and were not significant.

\section{DISCUSSION}

Uroflowmetry with PVR determination is an important and widely used urodynamic testing for evaluation of voiding dysfunction. Although it does not discriminate bladder outlet obstruction from detrusor muscle insufficiency, however it can give valuable objective data about both degree of obstruction and affectivity of the treatment. As micturition is a dynamic event, various external and internal factors may influence this event. External factors are generally related to the patients namely; age, sex and psychological characteristics, whereas internal factors are mainly composed of the anatomical properties of lower urinary tract and corresponding tissues. Neurological innervations of bladder and urethra and the biomechanical properties of detrusor muscle, urethra and urethral meatus are the main determinants of micturition in all voiding models. ${ }^{7}$ Rad et al (2002) reported that the average angle between rectum and anal canal was $92 \circ$ whilst sitting and $132 \circ$ when squatting. ${ }^{11}$ They concluded that this may cause relaxation of puborectalis muscles easing bladder and bowel evacuation. ${ }^{11}$ In another study by Bockus et al (1994), the author reported that sitting position stretches the puborectalis muscle which slightly close urogenital hiatus. ${ }^{8}$ Although there were no significant difference for Qmax and Qave values of patients in standing and squatting positions whilst voiding In our study the study showed that PVR was significant lower when squatting during voiding and it was statistically significant $(41.97 \mathrm{ml}$ vs $38.28 \mathrm{ml}$ with $P$ value of $<0.05$ ).

There are very limited studies evaluating the changes of uroflowmetric parameters related to voiding position other than patients' daily life habit. In a study designed by El-Bahnasawy et al (2008), where participants void in sitting position because of cultural traditions or demands of the religious, authors found no difference in uroflowmetry parameters, whereas patients had significantly higher PVR values at standing position. But this difference between the mean PVR was not over 15 $\mathrm{mL}(73 \pm 80.2$ in sitting and $86.1 \pm 77$ in standing position). ${ }^{10}$ Although the author did not find any significant difference in their studies, they concluded that obliging the patients to void in a position to which they are not familiar may alter micturition act and might produce higher cerebellar inhibitory effect during voiding. ${ }^{10}$ In our study, majority of patients practice standing whilst voiding. In both group (squatting and standing) patients had higher Qmax values when they performed uroflowmetry evaluation in their natural position and this relation was however not significant.

Different voiding positions other than sitting and standing were also evaluated by some authors. Aghamir et al (2005), also evaluated crouching position and report no difference in uroflowmetry parameters. ${ }^{3}$ Similar conclusion was also reported by Unsal et al (2004), that crouching position did not alter uroflowmetry parameters in healthy males. ${ }^{14}$ Although sitting position was seem to be advantageous than standing position, Eryildirim et al (2006) reported no difference between sitting and squatting position. ${ }^{12}$ On the other hand, Amjadi et al (2006) reported a significant improvement of uroflowmetry parameters of obstructed patients as they micturating in crouching position. ${ }^{4}$ Our entire study group was using standing or sitting position in their daily life. Different theories had been proposed to define the effect of voiding position on uroflowmetry parameters. According to ElBahnasawy et al (2008), patients who void in the sitting position throughout their lives will have micturition reflexes modified and conditioned to this position. ${ }^{10}$ Amjadi et al (2006) proposed that relaxation of pelvic floor musculature may be a reason for decrease in bladder outlet resistance and abdominal musculature hence increase intraabdominal pressure helping micturition in crouching position. ${ }^{4}$ This may be true for crouching position but it does not seem to work in sitting position according to our study. Although we did not find significant uroflowmetry differences between voiding positions, we have similar results with Choudhury et al (2010) and Uluocak et al (2008) who demonstrated a decrease in uroflowmetry parameters in sitting position.${ }^{15}$ luocak et al (2008) reported that patients may have lower voiding detrusor pressure in sitting position. ${ }^{15}$ On the other hand gravity, slower detrusor contractions and altered geometry of bladder may be an advantage for voiding in standing position. Uroflowmetry evaluation is a popular and frequently used test that has been performed by many centres worldwide. Although we had a large number of patients in our study, this may not be enough to make a direct conclusion for general population. In order to understand the true effects of voiding position on uroflowmetry parameters, better well-organized, prospective studies with higher number of participants are needed. 
Islam is a comprehensive religion paying special attention of humanity which includes methods of treating sickness. From the Islamic perspective, a fellow Muslim is encouraged to sit or squat during micturition mainly for cleanliness purposes (anNasa'i; Majah; Majah; Majah). This has been quote many times by Prophet Muhammad (PBUH) in hadith. ${ }^{16-19}$ There were no specific reasons mentioned but we believed there are some scientific benefits that yet have to be explained. Awareness regarding the benefit of voiding in squatting position has also been discussed. ${ }^{5}$ The awareness to practice Islam in all aspect of life has brought many Muslims to realize the importance of following the shari'ah. According to Ibn al-Qayyim, shari'ah is aimed for governing individual and society affairs in life so it upholds justice, mercy, wisdom and common good in human dealings. ${ }^{20}$ It is the obligation of a Muslim physician to comply to shari'ah wherever they work. They should try their best to building the system those appeals to Muslim diaspora. ${ }^{21}$

\section{LIMITATION}

Supplementary squatting toilet was provided as optimal however many are adapted to normal standing position and find it difficult to void in squatting positions. This is true especially in those who never performed in such position before. Though sample calculation suggests 123 patients were sufficient, however a larger sample size can give a better research outcome as to whether squatting is better than sitting for BPH patients when voiding.

\section{CONCLUSION}

This study showed that voiding in squatting position, which is shari'ah compliant is not inferior compare to standard uroflowmetry, yet had showed some positive better outcome in some parameters. Therefore Muslim patients should be given the option to perform uroflowmetry in squatting position if available and possible better and improved results will be obtained in squatting position.

\section{ACKNOWLEDGEMENT}

This study was carried out with the fullest cooperation form the members of the Urology Department HTAA.

\section{REFERENCES}

1. Kinder, MV, Bastiaanssen, EH, Janknegt, RA, \& Marani, E. Neuronal circuitry of the lower urinary tract; central and peripheral neuronal control of the micturition cycle. Anat Embryol (Berl) 1995; 192:195-209.

2. AbdelMagid, ME, \& Gajewski, JB. Critical review of the uroflowmetry. Can J Urol 1998; 5:569575.
3. Aghamir, SM, Mohseni, M, \& Arasteh, S. The effect of voiding position on uroflowmetry findings of healthy men and patients with benign prostatic hyperplasia. Urol J 2005; 2:216 $-221$.

4. Amjadi, M, Madaen, SK, \& Pour-Moazen, H. Uroflowmetry findings in patients with bladder outlet obstruction symptoms in standing and crouching positions. Urol J 2006; 3:49-53.

5. Isbit, J. Nature Knows Best: Health Benefit of The Natural Squatting Position. North Carolina, USA, 2008.

6. Ather, $\mathrm{MH}$, \& Memon, A. Uroflowmetry and evaluation of voiding disorders. Tech Urol 1998; 4:111-117.

7. Bastiaanssen, $\mathrm{EH}$, van Leeuwen, JL, Vanderschoot, J, \& Redert, PA. A myocybernetic model of the lower urinary tract. J Theor Biol 1996; 178:113-133.

8. Bockus, HL (Ed). Gastroentrology (Vol. 2). Philadelphia: Saunders Co, 1994.

9. Choudhury, S, Agarwal, MM, Mandal, AK, Mavuduru, R, Mete, UK, Kumar, S, \& Singh, S K. Which voiding position is associated with lowest flow rates in healthy adult men? role of natural voiding position. Neurourol Urodyn 2010; 29:413 $-417$.

10. El-Bahnasawy, MS, \& Fadl, FA. Uroflowmetric differences between standing and sitting positions for men used to void in the sitting position. Urology 2008; 71:465-468.

11. Rad, S. Impact of Ethnic Habits on Defecographic Measurements. Arch Iranian Med 2002; 5:115-117.

12. Eryildirim, B, Tarhan, F, Kuyumcuoglu, U., Erbay, E, \& Pembegul, N. Position-related changes in uroflowmetric parameters in healthy young men. Neurourol Urodyn 2006; 25:249-51.

13. Malaysia, $\mathrm{MoH}(\mathrm{Ed})$. Malaysian Guideline for Good Clinical Practice (Third ed). Petaling Jaya: National Comittee for Clinical Research. 2011

14. Unsal, A, \& Cimentepe, E. Voiding position does not affect uroflowmetric parameters and postvoid residual urine volume in healthy volunteers. Scand J Urol Nephrol 2004; 38:469471.

15. Uluocak, N, Oktar, T, Acar, O, Incesu, O, Ziylan, $O$, \& Erkorkmaz, U. Positional changes in voiding dynamics of children with nonneurogenic bladder dysfunction. Urology 2008; 72:530-534.

16. an-Nasa'i, S The Book of Purification. Book 1, Vol. 1(Hadith 29).

17. Majah, SI The Book of Purification and its Sunnah. Book 1, Vol 1 (Hadith 309).

18. Majah, SI The Book of Purification and its Sunnah. Book 1, Vol. 1(Hadith 341).

19. Majah, SI The Book of Purification and its Sunnah. Book 1, Vol. 1(Hadith 308).

20. Ibn Qayyim. Healing with the medicine of the Prophet. (English version) Maktabar Dar us Salam Second Edition, 2003.

21. Rahman, MK \& Zailani S. Understanding Muslim medical tourists' perception toward Islamic 
friendly hospital. Hospitality \& tourism management 2016; 1:15-22. 
